Note

\title{
Potential of an Antagonistic Bacterium Serratia marcescens Strain B2 for the Biological Control of Cucumber Damping-Off Disease
}

\author{
NOBUTAKA SOMEYA ${ }^{1,2 *}$, MASAMI NAKAJIMA ${ }^{1}$, AND KATSUMI AKUTSU ${ }^{1}$ \\ 'School of Agriculture, Ibaraki University, Ami-machi, Ibaraki 300-0393, Japan \\ Present address: ${ }^{2}$ National Institute for Agro-Environmental Sciences, \\ 3-1-3 Kannondai, Tsukuba, Ibaraki 305-8604, Japan
}

Received 22 December 2004/Accepted 1 February 2005

\begin{abstract}
The cell suspension (ca. $10^{9} \mathrm{CFU} / \mathrm{ml}$ ) of an antagonistic bacterium Serratia marcescens strain B2 was inoculated into the soil of the cucumber rhizosphere. The pathogen Rhizoctonia solani Kühn AG-4, which causes damping-off disease, was challenge-inoculated to the cucumber seedlings. Disease incidence with bacterial treatment was reduced to about $45 \%$ compared with that of the untreated control. The strain B2 survived in the soil of the rhizosphere under glasshouse conditions at ca. $10^{6}$ to $10^{7} \mathrm{CFU} / \mathrm{g}$ soil for $4 \mathrm{wk}$ after application. Production of lytic enzyme chitinases and antibiotic prodigiosin by the strain B2 was enhanced under the presence of fungal hyphae. These results suggested that the strain B2 has a potential as an effective and long-lasting biological control agent to deal with cucumber damping-off disease.
\end{abstract}

Key words : Biocontrol/Chitinolytic enzymes/Cucumber damping-off/Rhizoctonia solani AG-4/ Serratia marcescens.

Public concern about the negative impact of chemical fungicides on human health and the environment has led to the intensified search for alternative methods to control plant diseases. The biological control of plant diseases by antagonistic microorganisms holds great promise (Campbell, 1989; Konno et al., 2001; Shoda, 2000). An gram negative bacterium, Serratia marcescens, is known as an opportunistic mammal or plant pathogen (Hejazi and Falkiner, 1997; Rascoe et al., 2003), but nonpathogenic strains of $S$. marcescens are known to be a useful biocontrol agent of phytopathogens or the plant growth-promoting rhizobacterium (Liu et al., 1995; Okamoto et al., 1998). One such biocontrol strain, $S$. marcescens strain B2, inhibits the in vitro growth of several phytopathogenic fungi, and controls cyclamen and rice fungal diseases (Akutsu et al., 1993; lyozumi et al., 1996; Someya et al., 2000; 2005).

${ }^{*}$ Corresponding author. Tel: +81-29-838-8268, Fax : +8129-838-8268.
Therefore, strain B2 is seem as an attractive biocontrol agent with excellent potential.

The damping-off of crop seedlings caused by Rhizoctonia solani Kühn AG-4 is responsible for considerable yield losses in a variety of crop plants. We have previously reported that the strain B2 suppressed cyclamen damping-off caused by $R$. solani AG-4. However, we have not yet demonstrated the effect of the strain B2 against the damping-off disease of other crops. The objective of the present study was to determine the suppressive effect of $S$. marcescens strain B2 against cucumber damping-off disease caused by $R$. solani AG- 4 .

S. marcescens strain B2 was isolated from the tomato plant and maintained in culture at Ibaraki University, Ibaraki, Japan. For bacterial growth, LuriaBertani medium agar (Sigma-Aldrich Japan, Tokyo, Japan) amended with $0.2 \%$ chitin (LBCA) was used. The damping-off pathogen, $R$. solani Kühn AG-4, was grown on potato sucrose agar (PSA) at $25^{\circ} \mathrm{C}$ in the dark. 
Four cucumber seeds (Cucumis sativus L., cv. Sagamihanjiro) were sown on $200 \mathrm{~cm}^{3}$ soil (vemiculite : peat moss $=1: 1, \mathrm{v} / \mathrm{v}$ ) in plastic pots, and grown in a glasshouse at $25^{\circ} \mathrm{C}$. Three days after germination, $10 \mathrm{ml}$ of bacterial suspension [ca. $1 \times 10^{9}$ colony forming units $(\mathrm{CFU}) / \mathrm{ml}$ ] or distilled water (control) were added into the soil of the rhizosphere $1 \mathrm{~h}$ before challenge inoculation with the pathogen. For comparison, $10 \mathrm{ml}$ of benomyl (benlate ${ }^{\circledR}$; Takeda Pharmaceutical Company Ltd., Osaka, Japan) solution (100ppm) or flutolanil (moncut $^{\mathrm{B}}$; Nissan Chemical Industries Ltd., Tokyo, Japan) solution (100ppm) was applied into the soil to compare their disease suppression with that of the bacterial treatment. For inoculation with the pathogen, a mycelial disc (5mm in diameter) of $R$. solani AG-4, cut from colonies grown on PSA, was placed on the soil in the center of the pot containing 4 seedlings. Pots were kept for $7 \mathrm{~d}$ under glasshouse conditions. Three pots were used for one experiment, and each experiment was repeated three times. Disease development was assessed $7 \mathrm{~d}$ after pathogen inoculation, and disease severity was evaluated based on the proportion of diseased (damping-off) seedlings. The mean disease severity for each experiment was statistically analyzed using Tukey's method (Tukey, 1984).

In order to examine the population dynamics of the strain B2, $10 \mathrm{ml}$ of bacterial suspension (ca. $1 \times 10^{9}$ $\mathrm{CFU} / \mathrm{ml}$ ) was poured into the pots containing cucumber seedlings that were germinated $3 \mathrm{~d}$ before. One gram of soil from the cucumber rhizosphere was collected every week after bacterial inoculation. Soil samples were transferred to $9 \mathrm{ml}$ of washing buffer (0.1M phosphate, $0.1 \%$ peptone, $\mathrm{pH} 7.0$ ) in $25 \mathrm{ml}$ vials. Vials were shaken with a voltex mixer for 60 s, sonicated with a Sonorex Super RK255H sonicator (Bandelin electronic, Berlin, Germany) for 60s, and serially diluted with washing buffer. Each dilution was spread plated on LBCA plates containing 50ppm ampicillin and incubated for $72 \mathrm{~h}$ at $28^{\circ} \mathrm{C}$ in the dark. $3 \mathrm{~d}$ after incubation, colonies exhibiting a reddish pigment (prodigiosin) and chitinolytic haloes were counted to estimate the strain B2 population. Each experiment was repeated three times.

We previously reported that lytic enzyme chitinases and antibiotic prodigiosin play a role in the biocontrol efficacy of the strain B2. Next, to examine the effect of fungal hyphae on the chitinase and prodigiosin production by the strain $\mathrm{B} 2$, the chitinase and prodigisin biosynthesis by the strain B2 was observed under the presence or absence of fungal hyphae. R. solani AG4 was grown in liquid PS medium for $72 \mathrm{~h}$ at $25^{\circ} \mathrm{C}$ on a reciprocal shaker (125rpm). After incubation, the fungal hyphae were centrifuged at $18,480 \times g$ for 3 min. The fungal mycelia were autoclaved, and the mycelia were washed with sterile water for three times. The mycelia of $R$. solani or colloidal chitin were added into the liquid LB medium at $0.2 \%$. The strain B2 was incubated in liquid LB medium containing the fungal hyphae or chitin for $72 \mathrm{~h}$ at $28^{\circ} \mathrm{C}$ on a reciprocal shaker (125rpm). Following incubation, the bacterial cells were centrifuged as described, and the supernatant was filtered through a $0.20 \mu \mathrm{m}$ filter. The chitinolytic activity of the supernatants was measured by the method described previously (Someya et al., 2000). Next, prodigiosin was then purified from the cells by the method described previously (Someya et al., 2001). The purified prodigiosin was developed using thin-layer chromatography, and the prodigiosin was defined by the $R f$ value (Someya et al., 2004).

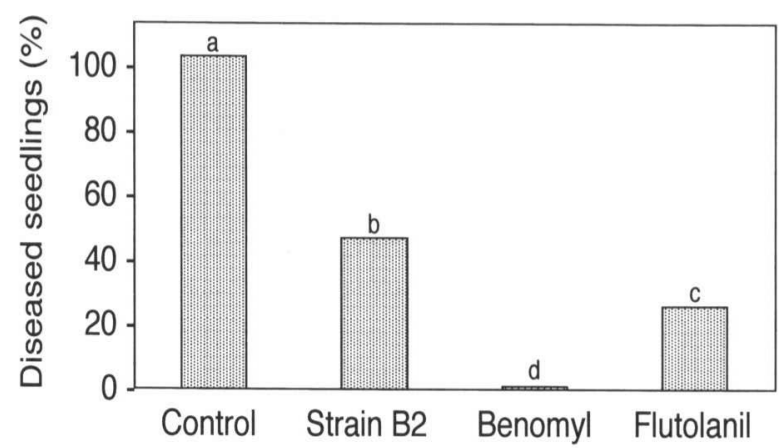

FIG. 1. Suppressive effect of Serratia marcescens strain B2 (strain B2) on the cucumber damping-off disease caused by Rhizoctonia solani Kühn AG-4. As comparisons, benomyl or flutolanil (100ppm) were applied into the soil to compare their disease suppression with that of the bacterial treatment. The letters indicate statistical significance as determined by the Tukey (1984) method ( $p$ $=0.05$ ).

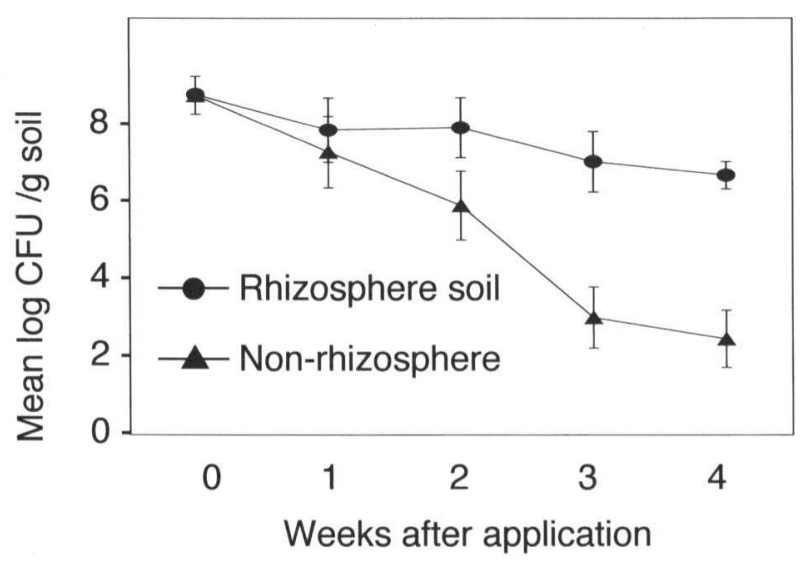

FIG. 2. Population dynamics of $S$. marcescens strain B2 in the soil of the cucumber rhizosphere under glasshouse conditions. Error bars indicate standard deviations. 
Growth of $R$. solani AG-4 was strongly inhibited by the strain B2 on LBA plates (Someya et al., 2000). In the biocontrol tests, the damping-off of cucumber seedlings occurred $7 \mathrm{~d}$ after inoculation with $R$. solani AG-4 in the absence of treatment by the bacterium or fungicides. On the other hand, the proportion of seedlings stricken with damping-off was reduced to about $45 \%$ when treated with the strain B2 (Fig. 1). The population of the strain $\mathrm{B} 2$ remained at ca. $10^{6}$ to $10^{7}$ CFU/g soil for 4 wk after application (Fig.2). The strain B2 did not cause any significant damage to cucumber seedlings during the test periods. We previously reported that this bacterium effectively contolled cyclamen damping-off and rice sheath
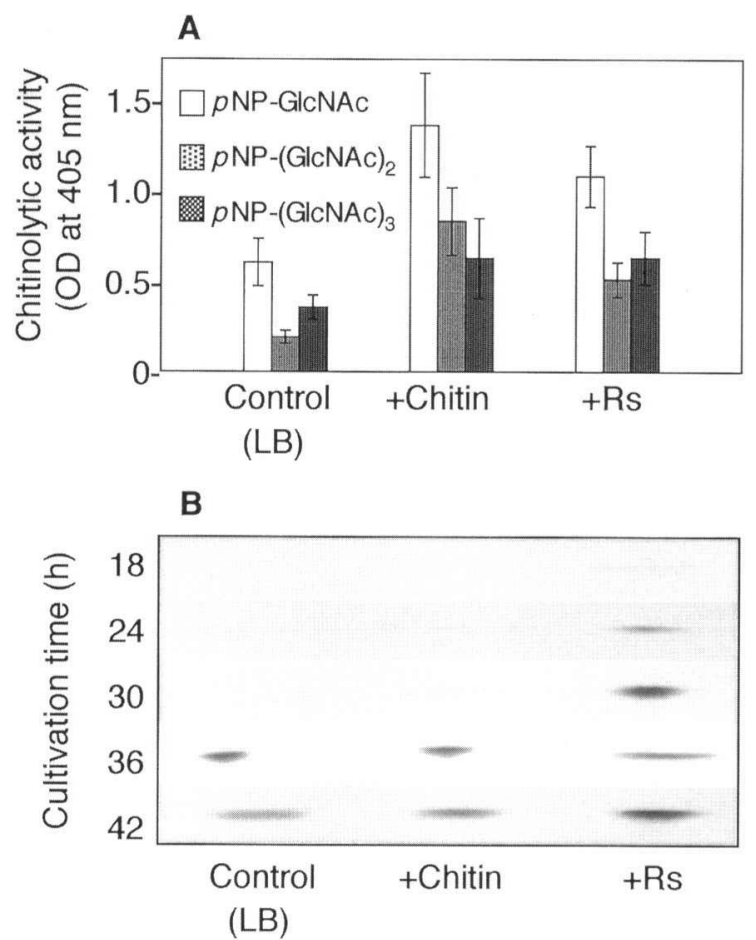

FIG. 3. Chitinase and prodigiosin production by $S$. marcescens strain B2 under the presence or absence of pathogen mycelia. $\boldsymbol{A}$ Chitinolytic activity in the culture filtrates of the strain B2 grown for $72 \mathrm{~h}$ in liquid LB medium containing colloidal chitin (+chitin) or R. solani AG-4 mycelia ( $+R s)$. The chitinolytic activity of the culture filtrates was estimated by the optical density $(405 \mathrm{~nm})$ of $p$ nitrophenol ( $p N P$ ) released from $N$-acetyl- $\beta$-D-glucosamine oligosaccharides substrate containing chromogenic derivatives of $p N P-G / C N A c$, $p N P-(G / C N A c)_{2}$, and $p N P$ $(G / C N A C)_{3}$ after $1 \mathrm{~h}$ incubation at $37^{\circ} \mathrm{C}$. The results are shown as the mean $(n=3) \pm$ the standard error. $\boldsymbol{B}$ Prodigiosin biosynthesis by the strain B2 under the presence of colloidal chitin (+chitin) or R. solani AG-4 mycelia $(+R s)$. Purified prodigiosin from bacterial cells were refractionated using silica gel thin-layer chromatography. Bands indicate prodigiosin, with an $R f$ value in the range of 0.90 to 0.95 . blight caused by $R$. solani. In the present study, we demonstrated that this bacterium also suppressed the cucumber damping-off caused by $R$. solani AG-4.

Regarding the biocontrol mechanisms, $S$. marcescens has multiple modes of action against phytopathogenic fungi such as the production of chitinases and prodigiosin (Okamoto et al., 1998; Someya et al., 2001). Velazhahan et al. (1999) reported the relationship between the antagonistic activity of bacteria against $R$. solani and their level of chitinase production. Actually, the chitinolytic activity of the culture filtrate of the strain B2 was increased in the presence of $R$. solani hyphae or colloidal chitin (Fig. 3A). It seemed that the chitinolytic activities of S. marcescens were increased by chitooligosaccharides released from fungal cell walls (Miyashita et al., 2000; Uchiyama et al., 2003; Ueno and Miyashita, 2000). In addition, the antibiotic pigment prodigiosin also acts as an antifungal factor against phytopathogens (Okamoto et al., 1998; Someya et al., 2001). The prodigiosin production by the strain B2 was also enhanced under the presence of fungal hyphae (Fig. 3B). However, the prodigiosin production was not enhanced by the colloidal chitin. The prodigiosin biosynthesis by Serratia is regulated by the quorum sensing via $\mathrm{N}$-acyl homoserine lactones (Thomson et al., 2000). However, the cell concentration of the strain B2 was not increased by the addition of fungal hyphae (data not shown). On the other hand, it is reported that the prodigiosin production by S. marcescens is also enhanced by fatty acids and some nutrimental factors (Cang et al., 2000; Gili et al., 2004). The prodigiosin production by the strain B2 might have been enhanced by the fatty acids released from the mycelia. We believe that both chitinases and prodigiosin synergistically suppressed pathogen infection in vivo. Moreover, some investigators have reported that some biocontrol agents including S. marcescens induce systemic resistance in various plants against phytopathogens (Liu et al., 1995), and we have previously reported that the strain B2 induces systemic resistance to rice blast in the rice plant (Someya et al., 2002). We hypothesize that various factors such as lytic enzyme chitinases, antibiotic prodigiosin and induced systemic resistance play a synergistic role in control of cucumber damping-off by the strain B2. This study has shown that S. marcescens strain B2 has potential as an effective and persistent biocontrol agent for the control of cucumber damping-off disease.

\section{REFERENCES}

Akutsu, K., Hirata, A., Yamamoto, M., Hirayae, K., 
Okuyama, S., and Hibi, T. (1993) Growth inhibition of Botrytis spp. by Serratia marcescens B2 isolated from tomato phylloplane. Ann. Phytopathol. Soc. Jpn., 59, 18-25.

Campbell, R. (1989) Biological Control of Microbial Plant Pathogens (Campbell R., ed.), Cambridge University Press, New York.

Cang, S., Sanada, M., Johdo, O., Ohta, S., Nagamatsu, Y., and Yoshimoto, A. (2000) High production of prodigiosin by Serratia marcescens grown on ethanol. Biotechnol. Lett., 22, 1761-1765.

Gili, A. V., Anandkumar, N., Muthukumaran, G., and Pennathur, G. (2004) A novel medium for the enhanced cell growth and production of prodigiosin from Serratia marcescens isolated from soil. BMC Microbiol., 4, 11-20.

Hejazi, A., and Falkiner, F. R. (1997) Serratia marcescens. J. Med. Microbiol., 46, 903-912.

lyozumi, H., Komagata, T., Hirayae, K., Tsuchiya, K., Hibi, T., and Akutsu, K. (1996) Biological control of cyclamen gray mould (Botrytis cinerea) by Serratia marcescens B2. Ann. Phytopathol. Soc. Jpn., 62, 559-565.

Konno, H., Uryu, S., and Furuya, H. (2001) Biological control of Rhizoctonia damping off disease using antagonistic fungus (in Japanese). Bokin Bobai, 29, 13-22.

Liu, L., Kloepper, J. W., and Tuzun, S. (1995) Induction of systemic resistance in cucumber against Fusarium wilt by plant growth-promoting rhizobacteria. Phytopathology, 85, 695-698.

Miyashita, K., Fujii, T., and Saito, A. (2000) Induction and repression of a Streptomyces lividans chitinase gene promoter in response to various carbon sources. Biosci. Biotechnol. Biochem., 64, 39-43.

Okamoto, H., Sato, M., Sato, Z., and Isaka, M. (1998) Biocontrol of Phytophthora capsici by Serratia marcescens $\mathrm{F}-1-1$ and analysis of biocontrol mechanisms using transposon-insertion mutants. Ann. Phytopathol. Soc. Jpn., 64, 287-293.

Rascoe, J., Berg, M., Melcher, U., Mitchell, F. L., Bruton, B. D., Pair, S. D., Fletcher, J. (2003) Identification, phylogenic analysis, and biological characterization of Serratia marcescens strains causing cucurbit yellow vine disease. Phytopathology, 93, 1233-1239.

Shoda, M. (2000) Bacterial control of plant diseases. J. Biosci. Bioeng., 89, 515-521.
Someya, N., Kataoka, N., Komagata, T., Hirayae, K., Hibi, T., and Akutsu, K. (2000) Biological control of cyclamen soilborne diseases by Serratia marcescens strain B2. Plant Dis., 84, 334-340.

Someya, N., Nakajima, M., Hirayae, K., Hibi, T., and Akutsu, K. (2001) Synergistic antifungal activity of chitinolytic enzymes and prodigiosin produced by biocontrol bacterium Serratia marcescens strain B2 against gray mold pathogen, Botrytis cinerea. J. Gen. Plant Pathol., 67, 312-317.

Someya, N., Nakajima, M., Hibi, T., Yamaguchi, I., and Akutsu, K. (2002) Induced resistance to rice blast by antagonistic bacterium, Serratia marcescens strain B2. J. Gen. Plant Pathol., 68, 177-182.

Someya, N., Nakajima, M., Hamamoto, H., Yamaguchi, I., and Akutsu, K. (2004) Effects of light conditions on prodigiosin stability in the biocontrol bacterium Serratia marcescens strain B2. J. Gen. Plant Pathol., 70, 367-370.

Someya, N., Nakajima, M., Watanabe, K., Hibi, T., and Akutsu, K. (2005) Potential of Serratia marcescens strain B2 for biological control of rice sheath blight. Biocontrol Sci. Technol., 15, 105-109.

Thomson, N. R., Crow, M. A., McGowan, S. J., Cox, A., Salmond, G. P. C. (2000) Biosynthesis of carbapenem antibiotic and prodigiosin pigment in Serratia is under quorum sensing control. Mol. Microbiol., 36, 539-556.

Tukey, J. W. (1984) Exploratory Data Analysis. Reading, MA, Addison-Wesley.

Uchiyama, T., Kaneko, R., Yamaguchi, J., Inoue, A., Yanagida, T., Nikaidou, N., Regue, M., and Watanabe, T. (2003) Uptake of $N, N^{\prime}$-diacetylchitobiose [(GlcNAc) 2 ] via the phosphotransferase system is essential for chitinase production by Serratia marcescens 2170. J. Bacteriol., 185, 1776-1782.

Ueno, H., and Miyashita, K. (2000) Inductive production of chitinolytic enzymes in soil microcosms using chitin, other carbon-sources, and chitin-producing Streptomyces. Soil Sci. Plant Nutr., 46, 863-871.

Velazhahan, R., Samiyappan, R., and Vidhyasekaran, P. (1999) Relationship between antagonistic activities of Pseudomonas fluorescens isolates against Rhizoctonia solani and their production of lytic enzymes. Z. Pflanzenk. Pflanzens. J. Plant Dis. Prot., 106, 244-250. 